\title{
THE RELIABILITY OF STERILISING ESMARCH BANDAGES
}

\author{
RAJAN ASIRVATHAM, HUGH G. WATTS, BETTY J. WARE, RONALD J. ROONEY
}

Gaines, Johnson and Manning (1987) have warned against the reliability of sterilising Esmarch bandages and have recommended that the use of conventionally sterilised Esmarch bandages should be abandoned. This did not agree with our experience, so we have reevaluated the subject experimentally and clinically.

Laboratory study. Ten Esmarch bandages, each $4.6 \mathrm{~m}$ long were loosely rolled, interleaved with a gauze bandage. Three biological indicators which contained spores of Bacillus stearothermophilus were inserted, one in the centre of the roll, one in the middle and one near the outer layer. The bandages were then placed in a prevacuum steam steriliser for four minutes at $132^{\circ} \mathrm{C}$. The biological indicators were removed and incubated at $57^{\circ} \mathrm{C}$ for seven days. They were observed each day for evidence of growth of the bacillus.

No growth of the bacilli was observed in any of the 30 biological indicators after seven days of incubation.

Clinical study. The charts of 385 patients, who had had operations on their lower limbs under pneumatic tourniquet control were reviewed (Table I).

In group A Esmarch bandages were used. The bandages were loosely rolled with interleaving gauze and then placed in one of two types of steriliser: in the prevacuum steriliser they were subjected to steam at $132^{\circ} \mathrm{C}$ for four minutes; in the gravity steriliser they were subjected to steam at $121^{\circ} \mathrm{C}$ for 30 minutes.

In group B, no Esmarch bandages were used. The two groups were comparable in age and sex distribution. Results. There was no statistical difference in the infection rate between the two groups. In the group in which sterile Esmarch bandages were used, there was one patient with

R. Asirvatham, FRCS Ed(Orth), Chief Orthopaedic Resident

B. J. Ware, RN, Supervisor CSSD

R. J. Rooney, MD, FACS, Chairman

King Faisal Specialist Hospital and Research Centre, PO Box 3354 Riyadh 11211, Saudi Arabia.

H. G. Watts, MD

The Shriner's Hospital for Crippled Children, 3160 Geneva Street, Los Angeles, California 90020-1199, USA.

Correspondence to Dr R. Asirvatham.

(C) 1990 British Editorial Society of Bone and Joint Surgery 0301-620X/90/5R84\$2.00

J Bone Joint Surg [Br] 1990; 72-B :924. definite pin-track infection and two with possible infections. All three 'infections' resolved with antibiotics and/or pin removal. In the groups with no Esmarch bandages, there were two patients with pin-track infections; both were successfully treated with antibiotics and removal of pins.

Table I. Details of the 385 patients who had lower limb operations

\begin{tabular}{lll}
\hline & $\begin{array}{l}\text { Group A } \\
\text { (Sterile } \\
\text { Esmarch used) }\end{array}$ & $\begin{array}{l}\text { Group B } \\
\text { (Esmarch } \\
\text { not used) }\end{array}$ \\
\hline Patients & 209 & 176 \\
Total admissions & 225 & 213 \\
Lower limb operations & 302 & 249 \\
Antibiotics used & 232 & 231 \\
\hline
\end{tabular}

Discussion. Gaines et al (1987) reported a high incidence of failure to obtain sterilisation of Esmarch bandages with standard autoclaving procedures. They tested two lengths of Esmarch bandages $(5.5 \mathrm{~m}$ and $3.7 \mathrm{~m})$, either rolled tightly or loosely folded without interleaving gauze bandage, and showed that the temperature between the layers never reached a satisfactory level. Our experiments showed that reliable sterilisation could be achieved. This success was probably because, in our study, the Esmarch bandages, before being placed in the steriliser, were loosely rolled and were interleaved with a gauze bandage; this allows heat to penetrate between the layers. Our clinical study confirmed the safety of this technique.

We conclude that it is safe to use an Esmarch bandage provided that, before being sterilised, it is loosely rolled, with a gauze bandage between the rubber layers.

No benefits in any form have been received or will be received from a commercial party related directly or indirectly to the subject of this article.

\section{REFERENCE}

Gaines E, Johnson R, Manning MP. The efficacy of sterilising Esmarch bandages: brief report. J Bone Joint Surg [Br] 1987; 69-B :671-2. 